\title{
AÇÕES ANTIMICROBIANA E ANTI-INFLAMATÓRIA DA Punica granatum L. (ROMÃ) NO TRATAMENTO DA DOENÇA PERIODONTAL: UMA REVISÃO DE LITERATURA
}

\author{
ANTIMICROBIAL AND ANTI-INFLAMMATORY ACTIONS OF Punica granatum L. (ROMAN) IN THE \\ TREATMENT OF PERIODONTAL DISEASE: A LITERATURE REVIEW
}

\begin{abstract}
ACCIÓNS ANTIMICROBIANA Y ANTIINFLAMATORIA DE Punica granatum L. (ROMANA) EN EL TRATAMIENTO DE LA ENFERMEDAD PERIODONTAL: UNA REVISIÓN DE LA LITERATURA
\end{abstract}

\author{
Débora Raquel Rousseou Barros Dantas Macedo¹, Helen Tayná Noca de Souza², \\ Mariana Vasconcelos Guimarães ${ }^{3}$
}

Submetido: $20 / 04 / 2020$

Aprovado: 26/06/2020

\begin{abstract}
RESUMO
Introdução: As doenças periodontais (DPs) consistem em patologias de alta prevalência associadas ao acúmulo de biofilme bacteriano e que, em seu nível mais avançado, pode levar à perda dentária. O biofilme bacteriano é o principal fator etiológico da DP, pois estimula a resposta inflamatória do hospedeiro, cuja exacerbação tem sido associada à progressão da gengivite para periodontite. Ferramentas farmacológicas capazes de interferirem potencialmente com o crescimento de bactérias e de modular a inflamação têm sido alvos de estudos científicos nas últimas décadas, visando reduzir as sequelas da periodontite. Neste contexto, destaca-se o uso de plantas medicinais, tais como a Punica granatum L., popularmente conhecida como romã. Objetivo: Revisar a literatura sobre os potenciais antimicrobiano e anti-inflamatório da romã nas DPs. Métodos: Foram consultadas as bases de dados Pubmed e Scielo em dezembro de 2019, selecionando-se artigos dos últimos 10 anos, com as seguintes palavras-chaves: Doença periodontal, Farmacologia, Fitoterapia e Romã. Resultados: Foram selecionados 9 estudos pré-clínicos e clínicos associados a este tema em questão. Dentre estes, embora em 2 estudos a romã não tenha prevenido a formação da placa bacteriana e/ou a inflamação de tecidos periodontais, 7 estudos demonstraram que o extrato da romã agiu contra micro-organismos da placa dental, apresentando efeito antibacteriano sobre alguns patógenos, como o Streptococcus mutans, e melhorou os sinais clínicos inflamatórios das DPs. Conclusão: Assim, ainda que mais relatos científicos sejam necessários, a romã parece apresentar efeito potencial para tratamento coadjuvante das DPs, sendo este associado às suas ações antimicrobiana e/ou anti-inflamatória.
\end{abstract}

PALAVRAS-CHAVE: Doença periodontal; Farmacologia; Fitoterapia e Romã

\section{ABSTRACT}

Introduction: Periodontal diseases (PDs) consist of highly prevalent pathologies associated with the accumulation of bacterial biofilm and which, at its most advanced level, can lead to tooth loss. Bacterial biofilm is the main etiological factor of PD, as it stimulates the host's inflammatory response, whose exacerbation has been associated with the progression of gingivitis to periodontitis. Pharmacological tools capable of potentially interfering with the growth of bacteria and modulating inflammation have been targets of scientific studies in recent decades, aiming to reduce the sequelae of periodontitis. In this context, the use of medicinal plants, such as Punica granatum L., popularly known as pomegranate, stands out. Objective: To review the literature on the pomegranate's antimicrobial and antiinflammatory potentials in PDs. Methods: Pubmed and Scielo databases were consulted in December 2019, select-

\footnotetext{
Especialização em andamento em Odontopediatria no Centro Universitário Doutor Leão Sampaio - UNILEÃO

Atualmente faz Especialização em Odontopediatria pelo Centro Universitário Cristhus - (UNICRISTHUS) e atua como pesquisadora com ênfase nas áreas de Odontopediatria e reabilitação oral.

3 Mestre em clínica odontológica, com ênfase em periodontia, e doutoranda em Farmacologia na Universidade Federal do Ceará. Docente nas áreas de Periodontia, Implantodontia, Farmacologia, Clínica Integrada e Estágio Supervisionado.
} 
AÇÕES ANTIMICROBIANA E ANTI-INFLAMATÓRIA DA PUNICA GRANATUM L. (ROMÃ) NO TRATAMENTO DA DOENÇA PERIODONTAL: UMA REVISÃO DE LITERATURA Débora Raquel Rousseou Barros Dantas Macedo, Helen Tayná Noca de Souza, Mariana Vasconcelos Guimarães

ing articles from the last 10 years, with the following keywords: Periodontal disease, Pharmacology, Phytotherapy and Pomegranate. Results: 9 pre-clinical and clinical studies associated with this topic were selected. Among these, although in 2 studies the pomegranate did not prevent the formation of bacterial plaque and / or inflammation of periodontal tissues, 7 studies demonstrated that the pomegranate extract acted against microorganisms in the dental plaque, showing antibacterial effect on some pathogens, such as Streptococcus mutans, and improved the inflammatory clinical signs of PD. Conclusion: Thus, even though more scientific reports are needed, the pomegranate seems to have a potential effect for adjunctive treatment of $P D$, which is associated with its antimicrobial and / or anti-inflammatory actions.

DESCRIPTORS: Periodontal disease; Pharmacology; Phytotherapy and Pomegranate

\section{RESUMEN}

Introducción: las enfermedades periodontales (EP) consisten en patologías altamente prevalentes asociadas con la acumulación de biopelículas bacterianas y que, en su nivel más avanzado, pueden conducir a la pérdida de dientes. La biopelícula bacteriana es el principal factor etiológico de la EP, ya que estimula la respuesta inflamatoria del huésped, cuya exacerbación se ha asociado con la progresión de la gingivitis a periodontitis. Las herramientas farmacológicas capaces de interferir potencialmente con el crecimiento de bacterias y modular la inflamación han sido objetivos de estudios científicos en las últimas décadas, con el objetivo de reducir las secuelas de la periodontitis. En este contexto, destaca el uso de plantas medicinales, como Punica granatum L., conocida popularmente como granada. Objetivo: Revisar la literatura sobre los potenciales antimicrobianos y antiinflamatorios de la granada en las EP. Métodos: se consultaron las bases de datos Pubmed y Scielo en diciembre de 2019, seleccionando artículos de los últimos 10 años, con las siguientes palabras clave: enfermedad periodontal, farmacología, fitoterapia y granada. Resultados: se seleccionaron 9 estudios preclínicos y clínicos asociados con este tema. Entre estos, aunque en 2 estudios la granada no previno la formación de placa bacteriana y / o inflamación de los tejidos periodontales, 7 estudios demostraron que el extracto de granada actuaba contra microorganismos en la placa dental, mostrando un efecto antibacteriano en algunos patógenos, como Streptococcus mutans, y mejoró los signos clínicos inflamatorios de la EP. Conclusión: Por lo tanto, aunque se necesitan más informes científicos, la granada parece tener un efecto potencial para el tratamiento complementario de la EP, que se asocia con sus acciones antimicrobianas y / $\mathrm{o}$ antiinflamatorias.

PALABRAS CLAVE: Enfermedad Periodontal; Farmacología; Fitoterapia Y Granada 


\section{INTRODUÇÃO}

As doenças periodontais são condições infectoinflamatórias frequentemente associadas ao biofilme, caracterizadas inicialmente por inflamação do tecido gengival, conhecida como gengivite, podendo progredir apicalmente e culminar em perda de osso alveolar e de ligamento periodontal, originando a periodontite ${ }^{1}$. A periodontite é uma das principais causas da perda dentária em adultos, que acomete indivíduos em todo o mundo, estando entre os problemas orais mais prevalentes ${ }^{2}$. O diagnóstico da periodontite é feito basicamente por exames clínicos e história da doença, sendo estabelecido a partir da detecção de perda tecidual instalada em sítios diversos da cavidade oral ${ }^{3}$.

Por muitos anos, a literatura considerou o biofilme bacteriano como um fator etiológico primário das doenças periodontais ${ }^{4}$. De fato, sabe-se da necessidade da presença de bactérias presentes para iniciar o processo infectoinflamatório característico destas doenças. No entanto, tem sido bem estabelecida a importância da exacerbação da resposta do hospedeiro frente ao desafio microbiano para a progressão da gengivite para a periodontite e, consequentemente, da perda óssea inflamatória que se instala ${ }^{5}$.

Assim, o tratamento não cirúrgico da periodontite baseia-se em controle mecânico do biofilme bacteriano através de medidas preventivas, como instruções de higiene oral, e de medidas terapêuticas, caracterizadas por raspagens, polimento coronário e alisamento radicular, visando reduzir a progressão da doença ${ }^{6}$.

Apesar de muito se conhecer sobre a patogênese da periodontite e de existirem formas de tratamentos bem estabelecidas na literatura, algumas ferramentas farmacológicas vêm sendo pesquisadas quanto ao seu potencial de inibição da formação do biofilme dental na superfície dentária ${ }^{7}$, bem como pelo seu potencial anti-inflamatório. Neste contexto, destacam-se os produtos de origem vegetal muitas vezes utilizados na medicina popular como agentes antissépticos e/ou anti-inflamatórios, sobretudo por apresentarem baixo custo e fácil acesso ${ }^{8}$.

Dentre várias plantas com potencial medicinal, está a Punica granatum L. (punicácea), popularmente conhecida como romã. Trata-se de uma planta cultivada em países de clima quente e frequentemente utilizada na medicina popular para tratamento de afecções da garganta ${ }^{9,10}$. A literatura relata uma vasta gama de constituintes químicos presentes nesta planta, dentre os quais podem ser citados os alcaloides e taninos, estes últimos sendo substâncias presentes na casca de vegetais e com provável capacidade de impedir a proliferação de micro-organismos, atuando como um eficiente antisséptico ${ }^{11}$. Além deste potencial antimicrobiano, acredita-se que a rica constituição química da romã seja responsável pelas suas várias propriedades biológicas, como anticancerígena ${ }^{12}$, imunomoduladora ${ }^{13}$ e especialmente, anti-inflamatória ${ }^{14}$.

Considerando que a periodontite é uma doença caracterizada por perda óssea inflamatória na presença de placa bacteriana, aliado ao conhecimento de que a romã vem se destacando na literatura em decorrência do seu poder de inibir bactérias e citocinas próinflamatórias, o objetivo do presente estudo é averiguar os principais resultados de pesquisas científicas atuais realizadas em animais e em humanos sobre os benefícios da associação da romã ao tratamento periodontal não cirúrgico da periodontite, sobretudo quanto ao controle secundário da perda óssea alveolar desta doença.

\section{MÉTODOS:}

Foi realizada uma busca em dezembro de 2019 por artigos científicos publicados dos últimos 10 anos nas bases de dados Pubmed e Scielo, utilizando as palavras chaves: Doença periodontal, Farmacologia, Fitoterapia e Romã. Dentre 51 artigos, 16 artigos apresentaram-se relevantes, dentre os quais foram selecionados 9 . Os artigos selecionados contemplaram pesquisas científicas pré-clínicas $(n=4)$ ou em humanos $(n=$ 5) que associam diretamente a utilização da romã, seja em administração local ou sistêmica, à periodontite, considerando os aspectos microbiológicos, inflamatórios e clínicos desta doença. Além disso, também foi incluída uma dissertação de mestrado em decorrência da originalidade de como foi realizada a pesquisa in vivo e por a mesma ter avaliado, de forma pioneira, os efeitos anti-inflamatório e antirreabsortivo do extrato na Romã na periodontite experimental em ratos.

Foram excluídos do presente estudo artigos que não fizeram tal associação de maneira direta, ou cujo objetivo principal da referida pesquisa não seja relacionado a avaliar a ação antimicrobiana e anti-inflamatória especificamente da romã na evolução da doença periodontal, bem como revisões de literatura. 


\section{RESULTADOS}

A formação do biofilme supragengival se dá a partir da colonização bacteriana na película adquirida inicialmente por bactérias gram-positivas anaeróbias facultativas e alguns gram-negativos anaeróbios, denominadas colonizadores iniciais ${ }^{15}$. Em seguida, ocorre a adesão subsequente de novas bactérias àquelas já aderidas, sendo estas chamadas de colonizadores secundários. Inicia-se, então, a formação de microcolônias, resultando no aumento da massa do biofilme e, assim, facilitando que microrganismos que não tenham a capacidade de aderência possam, agora, se integrarem à comunidade por agregação ${ }^{16}$. Já o biofilme subgengival é beneficiado pela proteção oferecida pela sua localização, já que os tecidos periodontais o protegem das condições encontradas no ambiente supragengival. O biofilme subgengival é frequentemente composto por bactérias gram-negativas, anaeróbias e proteolíticas ${ }^{17}$. Considerando o gradiente de oxigênio presente no ambiente subgengival, sabe-se que a bolsa é colonizada por vários micro-organismos, dentre os quais a maioria é gram-negativos anaeróbios ${ }^{18}$. Essas bolsas servem como reservatórios para as bactérias que, no futuro, poderão colonizar outros sítios ${ }^{19}$.

A resposta do hospedeiro, por sua vez, começa pela ativação de células inflamatórias residentes no tecido conjuntivo, tais como macrófagos e mastócitos, frente aos padrões moleculares bacterianos, como lipopolissacarídeos, que são presentes em bactérias gram-negativas $^{20}$. Inicialmente, ocorrem alterações vasculares caracterizadas por vasodilatação e aumento da permeabilidade vascular, possibilitando a migração de leucócitos adicionais presente no interior do vaso ${ }^{21}$. Com a evolução do processo inflamatório, pode-se verificar a presença ainda mais intensa de inúmeros mediadores da inflamação, tais como o fator de necrose tumoral (TNF)- $\alpha$, a interleucina (IL)-1 $\beta$, a IL-6 e os metabólitos do ácido araquidônico, especialmente, a prostaglandina $(P G) \mathrm{E}_{2}$, dentre outros ${ }^{22}$.

Tais mediadores inflamatórios são responsáveis por perpetuar a resposta do hospedeiro, a qual é instalada como mecanismo de proteção do mesmo para inibir a proliferação dos microorganismos ${ }^{23}$, porém, contrariamente, também se mostra capaz de ser potencialmente danosa aos próprios tecidos do indivíduo ${ }^{24}$. Neste contexto, vale salientar que estudos indicam não ser incomum que doenças inflamatórias crônicas, tal como a periodontite, sejam caracterizadas por perda óssea ${ }^{25}$. De fato, há inúmeros relatos de que TNF- $\alpha$ e IL- $\beta$ possuem atividades coincidentes ao alterarem o metabolismo ósseo, induzindo a proliferação dos precursores osteoclásticos e estimulando a ativação de osteoclastos maduros, ao passo que inibem a atividade osteoblástica ${ }^{26}$. Além destes mediadores, PGE $_{2}$ e IL-17 uma vez presentes no processo inflamatório, parecem também contribuir para o saldo líquido final de reabsorção óssea no processo de remodelação deste tecido ${ }^{27,28}$.

A literatura científica indica, em diversos estudos, um relacionamento aproximado entre o sistema imune e ósseo ${ }^{29,30,31}$. Sobre isso, vale salientar a função do eixo RANK/RANKL/OPG para a homeostase óssea. A reabsorção óssea se inicia com a proliferação de precursores dos osteoclastos imaturos, posteriormente há a diferenciação seguida da maturação celular, a degradação de matrizes orgânicas e inorgânicas do osso ${ }^{32}$. A osteoclastogênese é regulada por vários eventos que envolvem diversas biomoléculas, como RANK (receptor ativador do fator nuclear Kappa-B) e seu ligante, RANKL, incluindo a OPG, além das citocinas inflamatórias, que já foram citadas anteriormente neste trabalho.

O eixo RANKL/RANK/OPG é extremamente importante na regulação do metabolismo ósseo. A atividade, a formação e a diferenciação dos osteoclastos são reguladas por essas três proteínas. O RANK é um receptor membro da superfamília do receptor do fator de necrose tumoral que se associa a fatores relacionados ao receptor TNF e que está presente na superfície de pré-osteoclastos ${ }^{33}$. Assim, o processo de osteoclastogênese envolvendo estas biomoléculas se inicia a partir da ligação de RANKL a RANK, induzindo a formação de osteoclastos maduros a partir dos pré-osteoclastos, inibindo a apoptose dos osteoclastos maduros e, consequentemente, induzindo a reabsorção óssea ${ }^{34}$.

A OPG, por sua vez, é uma molécula solúvel produzida por células do ligamento periodontal, epiteliais e fibroblastos ${ }^{35}$, além dos próprios osteoblastos. Ela age impedindo a ligação RANKL ao seu receptor, levando, assim, à diminuição da osteoclastogênese ${ }^{36}$. A literatura parece ser consistente que a sub-regulação da OPG e a superregulação do RANKL estão envolvidas em várias doenças, como a osteoporose, a artrite reumatoide e a periodontite ${ }^{37}$, todas estas caracterizadas por perda óssea em resposta à presença constante de mediadores inflamatórios, especialmente IL-1, IL-17, TNF- $\alpha$ e PGE ${ }_{2}$.

$A$ romãzeira é nativa da região mediterrânea $e$ é cultivada mundialmente em regiões de clima quente. Esta planta forma arbusto que pode alcançar de 3 a 6 metros de altura, apresentando ramificações com formato de espinhos ${ }^{38}$. Suas folhas são simples e suas flores apresentam coloração vermelho-alaranjadas, enquanto 
seus frutos têm uma casca amarela ou avermelhada com sementes granulosas adocicadas ${ }^{39}$.

Em diversos estudos científicos, são utilizadas partes específicas desta planta: a flor, o fruto, a casca, o caule, as raízes ou as sementes. As cascas do fruto possuem atividade antisséptica e são muito utilizados no tratamento de dores de garganta e inflamações bucais ${ }^{40}$. Quanto a outros usos populares principais, pode-se citar o tratamento de úlceras, diarréia, febre, gengivite, abscessos, inflamações, aftas e vários outros tipos de infecções ${ }^{41}$.

A Punica granatum L. possui atividade antimicrobiana comprovada na literatura sobre diversos espécimes de bactérias, como a Streptococcus mutans. Além disso, foi avaliado o potencial antimicrobiano do extrato da casca da Punica granatum sobre 38 linhagens de Stapylococcus aureus de origem bovina, obtendo resultados, também, positivos ${ }^{42}$.

Um estudo in vitro mostrou o poder antimicrobiano da tintura da casca da romã a $20 \%$ frente Stapylococcus aureus e Streptococcus pyogenes ${ }^{43}$. Em outro estudo, verificou-se a atividade antimicrobiana do extrato da Punica granatum in vivo e in vitro em 16 linhagens de salmonela. Neste último estudo in vivo, os camundongos foram infectados com $S$. typhimurium e depois foram submetidos ao tratamento sistêmico com o extrato de romã, observando-se, após, que o extrato da romã apresentou atividade antibacteriana em todas as linhagens, inibindo $S$. typhimurium e também diminuindo a mortalidade de camundongos ${ }^{44}$.

Já em outro manuscrito, os autores investigaram dezessete plantas da índia quanto ao potencial antibacteriano das mesmas contra o agente causador de infecção urinária. A Punica granatum apresentou um grande potencial contra Escherichia colit5. Em outro estudo, foi realizado um ensaio clínico para avaliar os efeitos de bochechos de romã 2 vezes ao dia por 4 dias e observaram-se que os efeitos foram semelhantes ao da clorexidina. Neste mesmo estudo, a romã mostrou ser eficaz inibindo in vitro de cepas de Prevotella intermedia, Porphyromonas gengivalis e Actinomycetemcomitans, após inoculações in vitro e ainda demonstrou efeito antiplaca, comparável ao efeito da clorexidina, demonstrando diferenças significantes ao grupo placebo ${ }^{46}$. Além destas espécies bacterianas, um estudo avaliou a concentração inibitória mínima de extratos da casca da romã em cepas de candida albicans e candida parapsilosis, observando efeitos positivos ${ }^{47}$.

O potencial anti-inflamatório da Punica granatum tem demonstrado que a administração de romã em ratos com fibrose hepática leva a uma diminuição nos níveis de malindialdeído (MDA) e da atividade de mieloperoxidase (MPO), sendo esta uma enzima abundante em neutrófilos, reduzindo os níveis basais de estresse oxidativo e diminuindo danos ao DNA ${ }^{48}$. Adicionalmente, também foi avaliado o efeito anti-inflamatório da romã em ratos com colite aguda. Neste, observou-se que a inflamação na mucosa do cólon, assim como os níveis de $\mathrm{PGE}_{2}$ e de óxido nítrico foram reduzidos, além da reconstituição da microbiota do intestino através da romã.

Um estudo avaliando a atividade anti-inflamatória dos taninos hidrolisáveis isolados, in vitro com cultura de células e in vivo com ratos. Foi observado, no estudo in vitro, que os taninos presentes na Punica granatum inibiram a síntese de óxido nítrico e de prostaglandinas ${ }^{49}$. Assim, pesquisas científicas foram realizadas com o objetivo de verificar as ações antimicrobiana e anti-inflamatória da Punica granatum sobre a doença periodontal, onde se esperou que esta planta pudesse reduzir ou prevenir a progressão da perda óssea alveolar. De fato, as atividades anti-inflamatória e antirreabsortiva óssea da Punica granatum combinada ou não com irradiação com laser de baixa intensidade (ILBI) na periodontite induzida por ligadura em ratos Wistar foram avaliadas por um grupo de pesquisadores. Os animais foram divididos em um grupo controle, onde a periodontite foi induzida através da inserção de um fio de nylon-3.0, porém não houve algum tratamento, e testes, onde os animais foram submetidos à ligadura e tratados diariamente com a administração do extrato de Romã nas doses de 60, 180, 540 mg/kg, combinada ou não a laserterapia. Os animais foram eutanasiados, suas maxilas foram removidas e processadas para análises macroscópica, histométrica, histológica e marcação imunohistoquímica para fosfatase ácida tártaro-resistente (FAO), um marcador da atividade de osteoblastos. A indução da periodontite causou intensa perda óssea alveolar, redução sérica de FAO, destruição do ligamento periodontal, do cemento e intensa infiltração leucocitária. A Punica granatum, por sua vez, combinada ou não com ILBI reduziu a infiltração leucocitária e o número de neutrófilos, reduzindo ainda a perda óssea alveolar provavelmente às custas da inibição da ativação de osteoclastos, sem causar alterações sistêmicas importantes ${ }^{20}$.

\section{CONSIDERAÇÕES FINAIS}

Dentre várias propriedades que a Púnica granatum possui, destacam-se as atividades antimicrobianas e anti-inflamatórias que tornam a romã interessante como adjuvante ao tratamento periodontal não cirúrgico. 


\section{REFERÊNCIAS}

1 - Eke PI, Zhang X, Lu H, Wei L, Thornton-Evans G, Greenlund KJ, Holt JB, Croft JB. Predicting Periodontitis at State and Local Levels in the United States. J Dent Res. 2016; 95(5):515-22.

2 - Chambrone L, Lima APA, Chambrone LA. Prevalência das Doenças Periodontais no Brasil. Parte II. 1993 - 2003. Revista Odonto, São Bernardo do campo, SP, Metodista. 2008; 16(31).

3 - Gomes Filho IS, Macedo TCN de, Cruz SS da, Soledade KR, Trindade SC, Sarmento V de A. Comparação de Critérios que Determinam o Diagnóstico Clínico da Doença Periodontal. Revista Odonto Ciência - Fac. Odonto/PUCRS. 2006; 21(51).

4 - Socransky SS, Haffajje AD, Cugini MA, Smith C, Kent Jr RL. Microbial complexes in subgingival plaque. J Clin Periodontal. 1998; 25(2):134-44.

5 - Kinney JS, Ramseier CA, Giannobile WV. Oral Fluid-Based Biomarkers of Alveolar Bone Loss in Periodontitis. Annals of New York Academy of Sciences. 2007; 1098:230-251.

6 - worch KP, Listgarten MA, Korostoff JM. A multidisciplinary approach to the diagnosis and treatment of early-onset periodontitis: a case report. J Periodontol, Chicago. 2001; 72(1):96-106.

7 - Pereira JV, Vieira M do S, Higino JS, Sampaio FC, Alves PM, Araújo CRF. Estudos com o extrato da punica granatum Linn. (Romã): efeito antimicrobiano in vitro e avaliação clínica de um dentifrício sobre microorganismos do biofilme dental. Revista Odonto Ciência - Fac. Odonto/PUCRS. 2005; 20(49).

8 - Batista JFR. Potencial antibacteriano da punica granatum Linn. (romã) na odontologia: revisão de literatura. 2013. 47 f. TCC (graduação em odontologia) - Universidade Estadual da Paraíba, Campina Grande - PB. 2013.

9 - Salgado ADY, Maia JL, Pereira SL da S, Lemos TLG de, Mota OM de L. . Antiplaque and antigingivitis effects of a gel Containing punica granatum extract. A double - blind clinical study in humans. J Appl Oral Sci. 2006; 14(3):162-6.
10 - Navarro V, Villareal ML, Rojas G, Lozoya X. Antimicrobial evalution of some plants used in Mexican traditional medicine for the treatment of infectious diseases. J Ethnopharmacol. 1996; 53(3):143-7.

11 - Nóbrega DR de M. Avaliação clinica da efetividade de um enxaguatorio à base de romã (punica granatum Lin) sobre o controle do biofilme dental e inflamação gengival em escolares. 2012. 81 f. Dissertação (Mestrado em Odontologia, Clínica Odontológica) - Universidade Estadual da Paraíba, Campina Grande - PB, 2012.

12 - Kim ND, Mehta R, Yu W, Neeman L, Livney T, Amichay A, Poirier D, Nicholls P, Kirby A, Jiang W, Mansel R, Ramachandran C, Rabi T, Kaplan B, Lansky E. Chemopreventive and adjuvant therapeutic potencial of pomegranate (punica granatum) for human breast cancer. Breast cancer research and treatment. 2002; 71(3):203-17.

13 - Sastravaha G, Gasmann G, Sangtherapitikul P, Grimm WD. Adjunctive periodontal treatment with Centella asiática and punica granatum extracts in surpportive periodontal therapy. J. Int Acad Periodontol. 2005; $7(3): 70-9$.

14 - Catão RMR, Antunes MRP, Arruda TA, Pereira MSV, Higino JS, Alves JÁ, Passos MGVM, Santos VL. Atividade antimicrobiana "in vitro" do extrato etanólico de punica granatum Linn (romã) sobre isolados ambulatoriais de staphylococcus aureus. Rev Bras de Anal Clí. 2006; 38(2):111-114.

15 - Cardoso RJA, Gonçalves EAN. Periodontia - Cirurgia para implantes - Cirurgia Anestesiologia. São Paulo: Artes Médicas. V. 5, cap. 1, 2002.

16 - Loesche WJ, Syed SA. Bacteriology of human experimental gingivitis: effect of plaque and gingivitis score. Infect. Immun. 1978; (21):830-839.

17 - Trein MP, Togni L, Almeida VG, Rosing CK, Oppermann RV. Formação de biofilme em diferentes concentrações de oxigênio. Revista Odonto Ciência - Fac. Odonto/PUCRS. 2006; 21(53). 
18 - Antonini R, Kizzy C, Gabriela KF, Giselli S, Emilio LS. Fisiopatologia da doença periodontal. Revista Inova Saúde, Criciúma. 2013; 2(2).

19 - Socransky S, Haffajee A. The bacterial etiology of destructive periodontal disease: current concepts. $J \mathrm{Pe}-$ riodontol. 1992; 63:322-31.

20 - Monteiro LKB. Efeitos anti-inflamatório e antirreabsortivo ósseos da Punica granatum L. combinada ou não com laser de baixa intensidade na perda óssea induzida por ligadura em ratos. 2013. Dissertação (Mestrado em Odontologia, Clínica Odontológica) - Universidade Federal do Ceará, Fortaleza, 2013.

21 - Paizan ML, Martin JFV. Associação entre doença periodontal, doença cardiovascular e hipertensão arterial. Rev Bras Hipertens. 2009; 16(3):183-185.

22 - Artese L, Maciej JS, Adriano P, Daniel SF, Luciana AGC, Marcelo F, Tatiana O, Marcello P, Vittoria P, Jamil AS. Immuno histochemical analysis of inflammatory infiltrate in aggressive and chronic periodontitis: a comparative study. Clinical Oral Investigations. 2011; 15(2):233240.

23 - Naiff PF, Orlandi PP, Santos, MC dos. Imunologia da Periodontite Crônica: Uma Revisão de Literatura. Scientia Amazonia. 2012; 1(2):28-36.

24 - Madianos PN, Bobetsis YA, Kinane DF. Generation of inflammatory stimuli: how bacteria set up inflammatory responses in the gingiva. J Clin Periodontal. 2005; 32(6):57-71.

25 - Taubman MA, Valverde P, Han X, Kawai T. Imunne response: The key to bone resorption in periodontal disease. J Periodontol. 2005; 76:2033-41.

26 - Assuma R, Oates T, Cochran D, Amar S, Graves DT. IL-1 and TNF antagonists inhibit the inflammatory response and Bone loss in esperimental periodontitis. $J$ Imunnol. 1998; 160(1):403-9.

27 - Rescala B, Rosalem WJR, Teles RP, Fische RG, Haffajee AD, Socransky SS, Gustafsson A, Figueredo $\mathrm{CM}$. Immunologic and microbiologic profiles of chronic and aggressive periodontitis subjects. J. Periodontol. 2010; 81(9):1308-1316.
28 - Junior JNM de A. Análise da imuno expressão das proteínas IL-17, IL-23 e Roryt na patogenia da doença periodontal. 2015. 117 f. Tese (Doutorado em Patologia Oral) - Universidade Federal do Rio Grande do Norte, Natal, 2015.

29 - Lu HK, Chen YL, Chang HC, LI CL, Kuo MYP. Identification of the osteoprotegerin/receptor activator of nuclear factor-Kappa B ligand system in gingival crevicular fluid and tissue of patients with chronic periodontites. Journal of Periodontal Research. 2006; 41(4):354-360.

30 - Andrade FR, Souza DP, Mendonça EF, Silva TA, Lara VS, Batista AC. Expression of bone resorption regulators (Rank,Rankl, and OPG) in odontogenic tumors. Oral Surg. Oral Med. Oral Pathol. Oral Radiol. Endod. 2008; 106(4):548-555.

31 - Cochran DL. Inflammation and bone loss in periodontal disease. J Periodontol. 2008; 79(8)1569-76.

32 - Teiltelbaum SL. Bone resorption by osteoclasts. Science. 2000; 1504-8.

33 - KHOSLA S. Minireview: The OPG/RANKL/RANK system. Endocrinology. 2001; 142(12):5050-5055.

34 - Crotti T, Smith MD, Hirsch R, Soukoulis S, Weedon $\mathrm{H}$, Capone M, Ahern MJ, Haynes D. Receptor activator NF kappaB ligand (RANKL) and osteoprotegerin (OPG) protein expression in periodontitis. J. Periodontal Res. 2003; 38(4):380-387.

35 - Sabino APZ. Efeito do fluoreto no reparo ósseo em alvéolos de camundongos com diferentes densidades ósseas. Análise morfométrica. 2012. 165 p. Dissertação (Mestrado em Odontologia, Estomatologia e Biologia Oral) - Universidade de São Paulo, Faculdade de Odontologia de Bauru, Bauru, 2012.

36 - Judas F, Palma P, Falacho RI, Figueiredo H. Estrutura e dinâmica do tecido ósseo. Clínica Universitária de Ortopedia dos Huc-Chuc, 2012.

37 - Maclean C, Newberry S, Maglione M, Mcmahon M, Ranganath V, Suttorp M, et al. Systematic review: comparative effectiveness of treatments to prevent fractures in men and women with low bone density or osteoporosis. Ann Intern Med. 2008; 148(3):197-213. 
38 - Santos EB, Dantas GS, Santos HB, Diniz MFFM, Sampaio FC. Estudo estnobotânico de plantas medicinais para problemas bucais no município de João Pessoa, Brasil. Rev Bras Farmacogn. 2009 19:321-324.

39 - Menezes SMS, Pinto DMP, Cordeiro LN. Biologics activities in vitro and in vivo of Punica granatum L. (pomegranate). Rev Brasileira Med. 2008; 65:388-91.

40 - Catão MHC de V, Silva MSP da, Silva ADL da, Costa RO da. Estudos Clínicos com Plantas Medicinais no Tratamento de Afecções Bucais: Uma Revisão de Literatura. UNOPAR Cient. Ciênc. Biol. Saúde. 2012; 14(4):279-85.

41 - Torres CRG, Cubo CH, Anido AA, Rodrigues JR. Agentes antimicrobianos e seu potencial de uso na odontologia. Rev. Fac Odontol São José dos Campos. 2000; 3(2):43-52.

42 - Silva MAR, Higino JS, Pereira JV, Siqueira-Júnior JP, Pereira MSV. Antibiotic activity of the extract of punica granatum Linn. Over bovine strains of staphylococcus aureus. Brazilian Journal of Farmacognosy. 2008; 18(2):209-212.

43 - Trindade MP, Fonseca L, Juiz PJL. Atividade antimicrobiana da tintura da casca da romã (punica granatum) sobre cepas de staphilococcus aureus e streptococcus pyogenes: estudo in vitro. Revista Brasileira de Pesquisa em Saúde. 2009; 11(4):49-54.
44 - Jang-Gi Choi, Ok-Hwa Kang, Young-Seob Lee, Hee-Sung Chae, You-Chang Oh, Obiang-Obounou, et al. In Vitro and In Vivo Antibacterial Activity of Punica granatum Peel Ethanol Extract against Salmonella. Evid Based Complement Alternat Med. 2011; 2011.

45 - Sharma A, Chandraker S, Patel VK, Ramteke P. Antibacterial activity of medicinal plants against pathogens causing complicated urinary tract infections. Indian Journal of Pharmaceutical Sciences. 2009; 71(2):136-139.

46 - Bhadbhade SJ, Acharya AB, Rodrigues SV, Thakur $\mathrm{SL}$. The antiplaque efficacy of pomegranate mouthrinse. Quintessence int. 2011; 42(1):29-36.

47 - Endo EH, Cortez DAG, Ueda-Nakamura T, Nakamura CV, Dias Filho BP. Potent antifungical activity of extracts and pure compound isolated from pomegranate peels and synergism with fluconazole against candida albicans. Res. Microbiol. 2010; 161(7):534-540.

48 - Larrosa M, Gonzáles-Sarrías A, Yánes-Gascón MJ, Selma MV, Azorín-Ortuño M, Toti S, Tomás-Barberán $\mathrm{F}$, Dolara P, Espín JC. Anti-inflammatory properties of a pomegranate extract and its metabolite urolithin- $A$ in a colitis rat model and the effect of colon inflammation on phenolic metabolism. J Nutr Biochem. 2010; 21:717-25.

49 - Lee CJ, Chen LG, Liang WL, Wang CC. Anti-inflammatory effects of punica granatum Linne in vitro and in vivo. Food Chemistry. 2010; 118:315-322. 